\title{
The Moral Economy of Ready-Made Food ${ }^{1}$
}

\begin{abstract}
:
The aim of this paper is to develop and apply a framework to explore how moralities of consumption are constituted in and through markets. Using the case of ready-made foods, this paper argues moral economies are comprised through interactions between micro, meso and macro level processes in the form of instituted systems of provision, state regulation, collective food customs promoted though media, NGOs and lifestyle practitioners, and the everyday reflections of consumers. Building on a theoretical framework developed to understand the moral economy of work and employment (Bolton and Laaser, 2013), this paper explores how markets for ready-made food are incessantly negotiated in the context of moral ideas about cooking, femininity and individual responsibility. It focuses on 'new' market innovations of fresh ready-to-cook meal solutions and explores how these products are both a response to moralizing discourses about cooking 'properly', as well as an intervention into the market that offers opportunities for new moral identities to be performed. Using data gathered from interviews with food manufacturers and consumers, I advocate for a multi-layered perspective that captures the dynamic interplay between consumers, markets and moralities of consumption.
\end{abstract}

Keywords: Cooking; femininity; moral economy; morality; ready-meals;

The aim of this paper is to develop and apply a framework to explore how moralities of consumption are constituted in and through markets. Using the case of ready-made foods, I argue moral economies are comprised through interactions between micro, meso and macro level processes in the form of instituted systems of provision, state regulation, collective food customs promoted though media, NGOs and lifestyle practitioners, and the everyday reflections of consumers. Ready-made foods have long been 'tinged with moral disapprobation' (Warde, 1999, p. 518) with their use being tied to a symbol of lack of care for the self and others (Bugge and Almås, 2006; Evans, 2014; Cairns and Johnston, 2015). Yet, they are widely available in countries across the world, albeit with significant contextual variations, and the range and 
diversity of ready-made options have made it difficult to discern what 'ready-made' actually comprises (Glucksmann, 2014; Halkier, 2016). In spite of its growing popularity, convenience food is a 'normatively and culturally ambivalent food consumption category', linked on the one hand to ease and time-saving for consumers and on the other to poor health and unsustainable industrial food (Halkier, 2016, p. 2). This makes it an ideal probe for exploring how moralities about 'proper' food and eating are reproduced and sustained.

The term 'moral economy' is often associated with the social historian E.P. Thompson (1971) whose essay on food riots in eighteenth-century England explored how communities drew upon shared norms and customs of the older paternalist order to justify their protest at unfair grain prices. Yet Thompson's 'moral economy' conceptualized capitalist markets and moralities as incompatible, rehearsing an enduring analytical separation between the worlds of rational economic activity and relations of sentiment and solidarity, termed by (Zelizer, 2011, p. 5) as the 'separate spheres and hostile worlds doctrine'. Rejection of this dualism between economy and culture/morality has motivated a body of work within economic sociology that recognizes the importance of interpersonal relations and moral ties, institutional frameworks and material devices within the construction of all markets (Callon, 1998; Sayer, 2000; Fourcade and Healy, 2007; Harvey, 2007; Zelizer, 2011). Morality and markets are widely understood to be coconstituted yet insights from the field of economic sociology are not often brought into conversation with the sociology of consumption (although see Jackson, Ward and Russell, 2009 for a notable exception). The analytical approach developed in this paper offers a bridge between these two fields.

This paper proposes a framework for exploring how 'moral economies' are both formatted through institutional frameworks and shaped everyday by actors from within. It does so by developing a framework proposed to understand the moral economy of work and employment (Bolton and Laaser, 2013) and informed by three key thinkers (Polanyi, 1944; Thompson, 1971; Sayer, 2005, 2011). I add to this framework insights from new economic 
sociology to show how moral understandings of ready-made foods are shaped by and through forms of political economic organization and cultural mediation. Utilizing the multi-layered framework and theoretical traditions not often adopted for exploring food habits, it is possible to capture novel insights into the ways consumer's own evaluations of what constitutes 'good' food interact with the calls from various lifestyle and health professionals for better eating and cooking (as well as the practices of food manufacturers operating within a neo-liberal market with limited state regulation) to generate new markets. What is distinctive about the approach proposed is how questions about the morality of consumption are at its centre, providing not only a space for academic and societal critiques to comment upon the virtue of the market but also an opportunity for multiple visions of morality to shape new understandings of what good food means. Like Goodman et al.'s (2010) discussion of ethical foodscapes, the approach put forward reveals the boundaries between good and bad food are never fixed but are relationally defined through a complex that comprises both material and cultural contexts.

This paper begins with an overview of literature on ready-made foods, commenting on the inherently gendered nature of cooking and caring practices. I then introduce the moral economy framework before turning to data from two separate research projects on ready-made foods in the UK. Using a case study of 'new' market innovations of fresh ready-to-cook meal solutions, I show how moralities around cooking and care have created new markets for readymade foods. The paper concludes with a discussion of the usefulness of the framework and how it could be employed to study food and consumption practices more generally.

\section{Ready-made food, gender and care}

The distinction between homemade food as culturally valuable and ready-made foods as unacceptable has been surprisingly persistent in moral discourses around cooking and eating practices (Moisio, Arnould and Price, 2004; Short, 2006; Evans, 2014; Jackson, 2015). Yet defining what counts as ready-made or convenience food and what counts as homemade food is 
difficult because it is dependent on historical and cultural context (Short, 2006). What was considered ready-made at one time and place (a loaf of bread or can of tuna fish, for example) is not popularly understood as ready-made at another. The range of ready-made foods and the innovation around this product category has increased in recent years, from ready-to-heat options that consumers can microwave and eat within minutes, to meal-kits which require consumers to assemble or cook their meals from pre-prepared parts (such as pre-chopped vegetables/meat).

Studies of ready-made/convenience foods suggest it is largely normalized, although to different degrees within different countries and cultural contexts (Carrigan, Szmigin and Leek, 2006; Gatley, Caraher and Lang, 2014; Glucksmann, 2014; Jackson, 2015; Halkier, 2016). In a study comparing French and British cooking habits, Gatley et al (2014) reveal that although French consumers use ready-prepared ingredients, they were less likely to use totally prepared ready-meals than their British counterparts. The authors point to the importance of French national cooking traditions which have remained locally-based and less influenced by ethnocuisines from migrant cultures. This contrasts with Glucksmann's (2014) study of ready-made foods in Britain where consumers have embraced a range of ethnic cuisines which were never previously cooked at home. Halkier (2016) suggests convenience foods are largely accepted as a way of life amongst young Danes, although consumers still normatively categorize these foods depending upon the social occasion. The acceptability of ready-made food depends upon how often and by whom this food is consumed (Evans, 2014). Those with responsibility for cooking for children and partners (predominantly women) frequently display guilt or shame when admitting to using convenience foods, reflecting on its antinomy with values of care (Warde, 1997; Moisio, Arnould and Price, 2004; Jackson, 2015).

Classic studies highlight the bulk of responsibility for food-work falls to women (Charles and Kerr, 1988; DeVault, 1991) and time-use studies reveal this gendered division of labour persists (Holm et al., 2015), although men do report cooking for leisure (Szabo, 2013). Just as 
DeVault (1991, p. 118) found 'by feeding the family, a woman conducts herself as recognizably womanly' so, in their recent study of food and femininity, do Cairns and Johnston (2015) highlight how American and Canadian women placed great importance upon providing healthy and 'good' food for their families. Women are the guardians of their family's health and tastes and most of the women in their study aspired to raise an 'organic child', although material constraints meant not all could achieve this. Conversely Carrigan et al. (2006) suggest ready-made foods can be used by mothers as a way of demonstrating their care and love for their children, providing convenient ways of handling busy working schedules and catering to diverse family tastes. Whether ready-made meal solutions are considered morally appropriate for enacting caring relations must be negotiated in the context of everyday contingencies, as well as through visions of 'proper' food and cooking which are both practiced by concerned mothers and shaped within a broader moral economy of 'careful' food (Lavis, Abbots and Attala, 2015).

Discourses of care are central to the ways food choices and practices are governed yet what constitutes care is widely contested. One need only look to the range of celebrity-chef media to see how ideas about proper food are tied up with ideas of self-control, responsibility and class cultures which can generate quite different understandings of what careful eating and 'good taste' implies (Hollows and Jones, 2010; Rousseau, 2012; Johnston and Goodman, 2015) Consumers draw on these available cultural repertoires, which state-led interventions, public health discourses, producers, advertisers, lifestyle practitioners, alternative consumption movements and food media all play a role in creating, to justify and construct certain food practices as either acceptable or morally dubious to themselves and others (Goodman, Maye and Holloway, 2010; Lavis, Abbots and Attala, 2015). The cut off line between good and bad food commodities is rarely fixed and is instead the result of ongoing social and political conflict which is played out through the relational intersection of everyday evaluations of diverse consumers, the many voices that defend and legitimize food customs, the devices and institutional frameworks of the market, and the regulation and governance of food systems. It is this 
relational complex which can account for the moral ambiguity of ready-made foods and the need for a framework that captures how 'moral webs of meaning' are relationally performed within distinct socio-historical contexts (Goodman, Maye and Holloway, 2010, p. 1784).

\section{The moral economy framework}

'Moral economy' is defined as 'the study of the ways in which economic activities, in the broad sense, are influenced by moral-political norms and sentiments, and how conversely, those norms are comprised by economic forces' (Sayer, 2000, p. 80). Such a definition reflects a growing body of work within the field of economic sociology which view markets as neither an inherently civilising nor destructive entity but one that is incessantly negotiated (Callon, 1998; Fourcade and Healy, 2007; Harvey, 2007; Zelizer, 2011). Markets are not just viewed as embedded within culture (as Granovetter's (1985) thesis proclaims) but are understood as being produced through practices of human sense-making as 'explicitly moral projects, saturated with normativity' (Fourcade and Healy, 2007, pp. 299-300). The approach developed in this section seeks to build a bridge between the field of economic sociology and the sociology of food consumption.

In recent years, there has been a proliferation of studies using the term 'moral economy' to account for the rise of ethical consumption movements and food politics (Goodman, 2004; Jackson, Ward and Russell, 2009; Adams and Raisborough, 2010; Wheeler, 2014, 2017; Morgan, 2015; Wilson and Jackson, 2016). The concept has gained much currency in the field of human geography to explore how moralities are mobilized across geographical scales, reflecting established power asymmetries between producing and consuming countries. Whilst Morgan (2015) imagines food politics driven by moral economies operating outside of the political economy (rehearsing the hostile worlds/separate spheres position - Zelizer, 2011), Peter Jackson and colleagues have highlighted the interactions between political and moral economies (Jackson, Ward and Russell, 2009; Jackson, 2015; Wilson and Jackson, 2016). Political economies can be moralized through spatially contingent regulatory mechanisms and meanings on the one hand 
and moral economies can be enacted through existing structural inequalities associated with conventional capitalist political economies on the other. The approach developed here acknowledges Jackson's insights but argues there is a need for a framework that can capture those macro-level structural mechanisms through which moralities of consumption are constituted at the same time as meso and micro-level processes shape the everyday food choices and evaluations of appropriate consumer behaviour in the market. It is only by looking at these elements in relation to one another that we can understand the place of morality within the market.

I propose a framework for capturing this relational moral economy of consumption that builds on the work of Bolton and Laaser (2013) in the field of work and employment (see also Wheeler, 2014; 2017). The framework proposed by Bolton and Laaser draws together three strands of the study of moral economy from the writings of Karl Polanyi (1944, 1957), E.P. Thompson (1971), and Andrew Sayer $(2005,2011)$ into a holistic analytical frame that accounts for individual agency, institutionalized structures of community and political economy. I argue these three authors are crucial to understanding how morality and markets are co-constituted but their ideas can be extended through engagement with insights from new economic sociology (Callon, Millo and Muniesa, 2007; Bandelj, 2012). Although these are authors and theoretical traditions not normally associated with studies of food consumption, I will show how the insights they offer speak directly to persistent concerns and debates within the sociology of food. The framework begins with Polanyi's $(1944 ; 1957)$ (then groundbreaking) thesis that refutes the separatist position between market and society. Polanyi challenged the idea of the self-regulating market and instead argued all economies are underpinned by social, political and moral values which enable them to function. Polanyi's ideas have been central to the development of economic sociology, particularly his notion of market embeddedness, although he used the concept in different ways in The Great Transformation (1944) and his essay 'The Economy as Instituted Process' (1957). Nina Bandelj (2012) makes a useful distinction between 
them - 'embeddedness as a variable' and 'institutional embeddedness' - and both are crucial for the revised moral economy framework. In the first instance, the self-regulation of the economy through market prices is understood as a potentially destructive force that society must be protected from (the famous 'double movement') through powerful institutions, such as the state, who 'check the action of the market' to defend people and the planet (Polanyi, 1944, p. 79; Block and Polanyi, 2003). But viewing the state as a necessary regulator of the economy might foster a vision of some markets as embedded and others not (particularly the self-regulating market) which fails to moves us beyond the separate spheres of market and morality (Zelizer, 2011). So the concept of 'institutional embeddedness' (Bandelj, 2012) that characterized Polanyi's later work and his claim 'the human economy... is embedded and enmeshed in institutions, economic and noneconomic' (Polanyi, 1957: 250) is also required. This always-embedded understanding of the economy forces us to pay attention to how moral sentiments are configured in and through dynamic economic processes of production, distribution, exchange and consumption that are institutionalized in distinct socio-historical contexts.

These insights drawn from Polanyi and Bandelj connect to existing debates about the morality of ready-made foods in the UK. On the one hand, there has been a great deal of interest in the role of the state in governing and regulating the market to protect the wellbeing/health of its citizens and the environment through food policy (Lang, Barling and Caraher, 2009; Marsden et al., 2010). Lang et al. (2009) describe how there has been a growing recognition that marketized approaches are threatening to both public health and the environment, yet UK state food policy has lessened its control over economic sectors whilst enhancing its regulatory reach through promotion of new forms of self-governance (Lang, Barling and Caraher, 2009). In a neo-liberal policy context, it is self-governance of both industry and consumers which has become the key goal of state intervention (Defra, 2010). Accounts of nudge-style interventions to promote public health and voluntary reductions in levels of fat and salt by industry reveal an important dimension of the ways moral ideas are regulated and practiced in the market, but they 
cannot be understood without insights derived from an 'institutional embeddedness' perspective which connects such regulations to broader systems of food commodity provision. Studies of commodity chains and single commodity narratives (Fine and Leopold, 1993; Harvey, Quilley and Beynon, 2002; Dixon, 2003; Cook, 2004; Gereffi and Lee, 2009) reveal how the possibilities for intervention are shaped within complex global food systems.

State and institutional economic processes take us only so far when exploring moral economies because a macro-level lens fails to account for how different visions of morality become enmeshed within economic and non-economic institutions. We need to add another layer to consider how diverse communities and collective movements together resist and oppose what they deem to be unfair or destructive economic practices. It is for this reason the framework turns to the writing of E.P. Thompson (1971) on food riots to reveal the importance of collective consciousness and political struggles between different groups in societies. Thompson's claim people are the ‘bearers of historical customs and moral evaluations of their community' adds an important dimension (Bolton and Laaser, 2013, p. 513). Customs are born from shared socio-economic and cultural traditions of communities of people who are connected through social and ethical bonds. Paying attention to such customs reveals the 'struggles below the surface' that 'evaluate, re-negotiate, revise and re-establish' the legitimacy of the market system (ibid.: pp514-515). Adding to Thompson's ideas about customs, the framework proposed in this paper draws on insights from the new economic sociology on the performativity of the market (Callon, 1998; Callon, Millo and Muniesa, 2007) to open a space for the normative critiques of consumer capitalism to be embedded. The performative turn implies the ways different communities (including academics, businesses, civil society organizations, celebrity figures and community action groups) think about and understand the economy can actively shape it through a range of material and discursive devices that bring markets in line with moral ideas (Fourcade and Healy, 2007). 
Paying attention to how customs shape food cultures and the performativity of normative consumer critique within the market chimes with a great deal of work within Food studies, particularly those working in the area of ethical foodscapes (Goodman, Maye and Holloway, 2010; Cairns and Johnston, 2015; Jackson, 2015). To take one example, the growing body of work around the influence of celebrity chefs and food cultures highlights how these public figures use their celebrity status to comment upon what they see as 'bad' examples of food provisioning (ready-meals and convenience foods) at the same time as they legitimatize their own visions of cooking from scratch through community-led intervention within both political debates and through commercial markets they create (Hollows and Jones, 2010; Rousseau, 2012; Abbots, 2015; Jackson, 2015; Johnston and Goodman, 2015). Celebrity chefs play an important role in shaping collective customs around the morality of ready-made foods, opening moments of possibility for resistance, engagement and approval by different audiences (from NGOs to lifestyle bloggers) (Barnes, 2014), who then go on to re-make the market according to their own normative visions of good food and eating.

So far the framework has focused on the way institutional and community norms shape the market but this leaves open possibilities for moral agency of people reflecting on the things that matter to them in their everyday lives. Public discourses offer useful 'rationales' that guide how people think about their practices, but these same discourses are 'open to different interpretations and uses... [and] contain inconsistencies and contradictions making them open to challenge from within' (Sayer, 2005: 7). Recognition of the plurality of people pursuing 'different and often contradictory goals in life, dovetailing commitments and concern about things that matter to them' provides the foundation of the final layer of the moral economy framework (Bolton and Laaser, 2013, p. 515). Humans are deeply 'evaluative ethical beings' who are capable of embracing or rejecting community norms, as well as offering reasons for participating in economic practices or not. Informed by Sayer's $(2005,2011)$ extensive work on the need for social scientists to take everyday morality seriously, the final layer seeks to bridge the gap 
between institutional/community norms and people's everyday reflective capacities. Here consumers' lay normativities - questions about 'what is of value, how to live, what is worth striving for and what is not' (Sayer, 2005, p. 6) - take centre stage, revealing the diversity and complexity of social and moral life. Using this lens, we can learn how everyday lay normativities are shaped within and against broader instituted systems of provision and cultural repertoires, recognizing the interdependent relationship between these elements that together constitute distinct moral economies of consumption. This more micro focus on everyday moralities occupies much scholarship within the sociology of food consumption, from accounts of how shopping for food and cooking enacts relationships of love and care (Miller, 1998; Carrigan, Szmigin and Leek, 2006) to feelings of guilt and pride in feeding the family properly (DeVault, 1991; Evans, 2014; Cairns and Johnston, 2015).

\section{The moral economy of ready-made food in the UK}

Figure 1: Moral Economy of consumption framework

4) Instituted system of provision

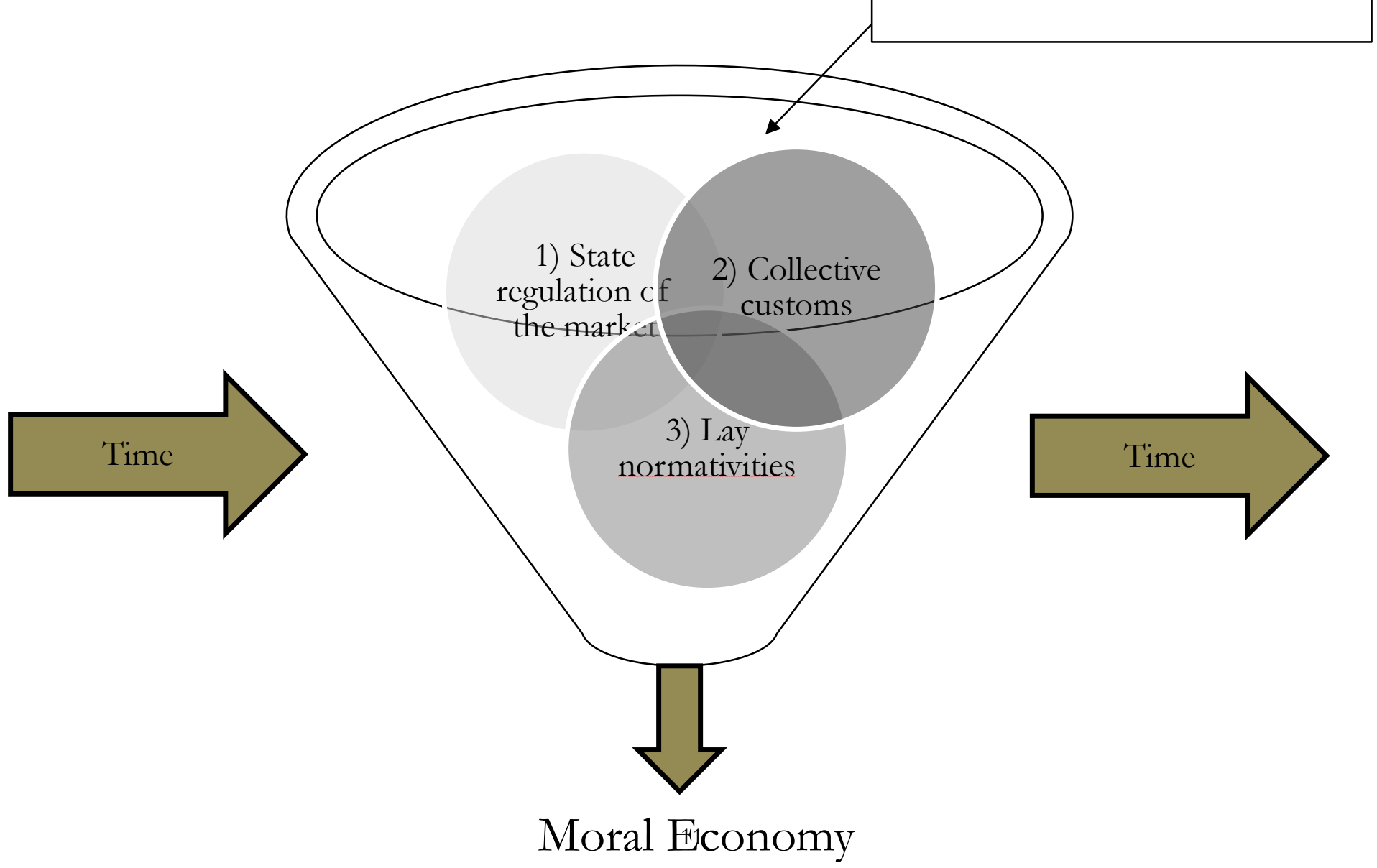


I am proposing three distinct layers of analysis for exploring moral economies of ready-made food consumption. These are, 1) state regulation of the economy, 2) the collective customs and critical discourse through which different groups in society actively moralise the market, and 3) the lay normativities of consumers. Figure 1 displays the framework as a Venn diagram to capture the relations of interdependency and interactions between the different layers of analysis. We can imagine these three layers (circles) moving around the edges of the funnel, each having the potential to push against the other, thus allowing structure and agency. Interactions and interdependencies between these three layers should be thought of as a dynamic relational complex configured through 4) a distinct 'instituted system of provision' (ISP) that represents the existing (but by no means fixed) organization of the provision of ready-made foods within socio-historical settings. Drawing on Harvey's (2007) concept of 'instituted economic processes' and Fine and Leopold's (1993) 'systems of provision', the instituted system of provision represents the dynamic inter-relations between economic processes and how these are 'historically instituted in space and at different scales, local, global and regional' (Harvey, 2007, p. 177). Emplacing the three layers within an 'instituted system' allows the always-embedded nature of the economy (Bandelj, 2012) as a moral/moralising force to be maintained. The funnel (ISP) may be more rigid and less pliable but it can be influenced by the three interacting layers of analysis. There is a temporal dimension to the model because moral economies are never fixed (Trentmann, 2007) but negotiated in the context of specific socio-historical contexts, meaning ideas about morality of ready-made foods can change. Taken together the framework will enable us to trace the distinctive configuration of the moral economy of ready-made food in the UK, and explore how visions of appropriate food and eating practices are enacted, challenged and reproduced through material devices and market forces. Before turning to this data, it is helpful to provide the reader with an overview of the system of chilled ready-meal provision within the UK (the funnel through which moralities are configured). 
After the US, the UK has the largest market for ready-meals in the world - worth $£ 3.1$ billion in 2015 (North, 2015). The author's own analysis of the ONS Living Costs and Food Survey (formerly the Expenditure and Food Survey) reveals fairly constant levels of household consumption between 2001-2011 - around 70 per cent of households consumed a fish, meat or vegetable ready meal during the two-week period in which they kept the diary. ${ }^{2}$ The ready-meals market is an incredibly dynamic sector dominated by retailer own-label systems of provision (Harvey, Quilley and Beynon, 2002). Supermarkets occupy a unique position in the UK - the majority of the population use supermarkets as their main source of purchased foods (Prior, Phillips and O’Driscoll, 2014), and supermarkets exercise extensive control over suppliers and manufacturers, as well as logistics and distribution (Harvey, Quilley and Beynon, 2002; Burch and Lawrence, 2005). When supermarket-own brands first appeared in 1970s, they were marketed as a value alternative to branded products. However, in the case of ready-meals the situation is quite different because branded manufacturers of this type of food were 'never seriously there' (Harvey, Quilley and Beynon, 2002, p. 179). Own-brand ready meals account for over 90 per cent of the market, with a focus on premium and novel cuisines (Key Note, 2013). The 'big four' supermarkets (Tesco, Sainsbury's, Asda and Morrisons) are in competition with one another for customers. Retailers use chilled ready-meals as part of their own-brand portfolio to compete for customers' patronage and unlike branded manufacturers can benefit from their close relationship to the consumer (such as point of sale monitoring, customer loyalty schemes and market research data) to develop many new products which respond to current trends. Harvey et al.'s research inside food companies revealed how dedicated manufacturers provide 'own-brand' products for multiple retailers, with frequent 'refreshing' of the various ranges of prepared foods and a rapid lead-in process that branded manufacturers would be unable to cope with.

The ready-made and convenience food market has come under a great deal of scrutiny from various commentators in recent years, including celebrity chefs and public health 
professionals, because it is perceived to be unhealthy and environmentally unsustainable.

Discourses of 'good' food often stand in opposition to convenience products (Evans, 2014). In keeping with the neo-liberal approach to state regulation, as well as the dominance of retailer provision of this food category, the markets for ready-made foods have been subject to a range of voluntary and retailer-led forms of governance. The Public Health Responsibility Deal and the raft of social marketing and health education initiatives promoted through the Change for Life initiative have encouraged manufacturers to reduce levels of salt, fat and sugar and improve nutritional information labelling, whilst at the same time educating the consumer to choose more carefully. In the UK, food choices are individualized with bad choices being the responsibility of the consumer. It is in this context that ready-to-cook meal solutions have emerged. These products comprise a selection of raw and partly-cooked ingredients within one package which require consumers to assemble the parts into a meal through cooking processes.

Having outlined the moral economy framework and suggested how it could be utilized to help us understand how morals and markets are co-constituted, I now demonstrate its empirical application using the case study of ready-to-cook food solutions.

\section{Researching ready-made foods}

The data for this paper are somewhat unusual; they have been drawn from two separate research projects (the first of which the author was not involved in), and utilize a range of qualitative methods (expert interviews, focus groups and household interviews). The different types of research data have been deliberately selected because they represent different perspectives and lived realities of ready-made food markets and can therefore shed light on the different levels of analysis within the moral economy framework. Interviews with food manufacturers can offer insights into how forms of market regulation interact with popular understandings of convenience foods and models of the consumer, whilst focus group data provides rich insights 
into normative and shared understandings of good food. In-depth interviews with household members about their food provisioning, on the other hand, offers unique access to the lay normativities and everyday evaluations of ready-made foods and how these are negotiated in the context of individual/household biographies. In this sense, the data are used to illustrate the theoretical framework developed above.

The first data-set was created in 2007 [conducted by researcher X] with a focus on the division of food preparation work within/between food factories and the home. Researcher X visited and interviewed managers and designers at three large food manufacturers who supply cook-chill ready-meals to several of the major supermarket-chains in the UK. They created a wide range of ready-meals, from value to high-end options and described how they were innovating around this product category. Interviews took the form of day field visits to manufacturers with separate meetings with representatives from new product development, HR and production departments. Given that women continue to hold main responsibility for foodwork and for their family's health and care (DeVault, 1991; Cairns and Johnston, 2015), these expert interviews were complemented by three focus groups with twenty women from different socio-economic backgrounds asked to discuss how they used and understood ready-made foods.

Secondary analysis of qualitative datasets is growing in popularity and proponents point to the potential of gathering rich insights extending beyond or building upon the intentions of the original researcher (Corti et al., 2014). A key criticism of such re-use is the loss of original context the data was generated within; however, Corti et al. suggest arguments about context are often over-stated as much qualitative research is conducted within teams and contextual details can be partially provided through meta-data. In addition, because the second research project was led by the researcher who gathered the data for the first, some of the underlying context could be provided through detailed conversations with her, as well as access to her personal field-notes. 
The second data-set was created by myself in partnership with Miriam Glucksmann in 2012 and it sought to explore 'consumption work' and societal divisions of labour. I conducted thirty household interviews (fifty participants) in three locations within the UK (Essex, Shropshire and London) to uncover how food preparation is organized on an everyday basis and consumers' evaluative reflections on ready-made foods. Households were recruited by placing adverts into public spaces (like libraries, community centers and supermarkets) and sampled to ensure variation between urban/rural centres, socio-economic groups and stage in the lifecourse. Women in sampled households generally had main responsibility for food-work (except for one single person household and two households where the men did all the cooking).

The qualitative material from both projects was analysed by the author using a qualitative data analysis package (MAXQDA) which enabled me to conduct a focused thematic analysis around the three levels of the moral economy framework. As the purpose of this paper is to highlight the usefulness of the theoretical framework proposed, this sort of deductive analysis is appropriate. As Braun and Clarke (2006) highlight, researchers are always active participants in the creation of thematic codes, making choices that link to broader theoretical concerns. Two key themes emerged through this analysis; a) the innovative use of the category of ready-made by producers and consumers who sought to construct these foods as more moral; b) how gendered expectations around cooking remain central to the way this market is moralized.

In what follows, I draw on the different data sources described to explore the interactive and relational character of the moral economy framework focusing on these two key themes.

\section{Morality as a performance and product}

With own-brand ready-made foods offering such a profitable USP for retailers, food manufacturers need to find ways to innovate around this category, operating in a market where ready-made foods are both normalized and morally dubious. As described above, food policy in 
the UK has embraced the neo-liberal context in which responsibility for public health is achieved through voluntary, retailer-led forms of market governance (Lang, Barling and Caraher, 2009). Calls for traffic-light labelling and reductions in levels of salt and fat within processed foods are constantly shaping the types of food innovations manufacturers develop. The manufacturers interviewed believed current drives towards freshness, and cooking from raw ingredients are transforming the product category so consumers can feel 'proud' to consume them.
I think the latest term is "deconstructing meals", so what we're now saying is that as opposed to the product being completely finished for the consumer, we're actually leaving them with some work still to do, so that it overcomes the guilt trip that I think a lot of consumers have had with ready meals, is that they feel really bad that they've just taken it out of the fridge, stuck it in the microwave, three and a half minutes later it's on the table, and they've had very little interaction with it. I do think that Jamie Oliver, in particular, has influenced the mind-set at the moment, that people will now consider processing vegetables out of the field, themselves, as opposed to buying pre-peeled potatoes.

(Managing Director at a factory producing meals for Tesco) Manufacturers were quite aware consumers felt guilty about using convenience products and used this knowledge to innovate around the category of ready-made. This is not necessarily a new trend but rather the continuation of a longer trajectory, for example adding an egg to a packet cake-mix. We see the performative element of these 'new' (and older) types of ready-made foods, which give consumers a chance to 'feel like they've had an element of cooking, themselves' (Development director at a factory producing meals for multiple retailers) and in so doing shaping the acceptability of ready-made food for the consumer and within the self-governing market. By cooking with these pre-prepared ingredients, consumers construct themselves and the food they create according to a normalized vision of what good food comprises.

What is interesting is the women in our focus groups and household interviews were already performing their own version of this market innovation. Our respondents wanted to 'put their 
print' onto ready-made foods by adding a bag of salad, or placing different toppings onto pizza bases to 'disguise it a bit more as a homemade meal' and 'make it healthier'. This creative mixing transforms a market-made meal with its negative moral connotations to a homemade meal, with its morally superior associations (Moisio, Arnould and Price, 2004).

If I was to take a curry out of the freezer and put it in the oven and serve that to them I would feel I'd cheated. If I'd chopped the chicken myself and added the peppers and whatever I'd put in there and then poured a sauce in and cooked it like that way and then served it I wouldn't feel I was cheating, because I don't know how to make a sauce, I wouldn't feel I was cheating.

(Sarah, 43 yrs, works full-time as Personal Assistant, with children at home) Terms like 'cheating' were common in descriptions of everyday cooking and were often juxtaposed with an ideal image of 'proper' cooking from scratch, despite the fact this was rarely practiced. Cultural conventions around what constitutes proper cooking have been discussed at length elsewhere (Short, 2006; Evans, 2014; Halkier, 2016), but paying attention to how these conventions are re-produced and re-defined through interactions between lay normativities, collective customs and modes of market regulation adds an important dimension to existing work. Ready-to-cook innovations are both a response to the ways consumers evaluate and use ready-made foods in practice, as well as an active intervention into the moral economy of ready-made food. They open the possibilities for new conventions around ready-made to be performed in relation to a market that responsibilizes consumers and producers to take control of their own and the nation's health through the act of cooking.

Yet, it should not be forgotten, that ready-to-cook products are commodities like any other for sale within a capitalist economy through stores owned by a handful of powerful corporations. The political economy is refracted through norms around cooking from fresh ingredients and moral imperatives to be responsible for consumer health. These moral messages must be negotiated within commercial contexts to make a profit and gain market share. Crucially, this 'new' version of 
ready-made food is cheaper for manufacturers to produce as they do not have to expend energy on cooking and cooling.

So by making it healthier, it also then, you're selling the product as it is, which is a much bealthier perception that offers better value on the shelf, so you're able to respond in a really positive way to the increasing demand and competition amongst the retailers [...] we can sell that [ready-to-cook] cheaper than somebody who sells it cooked.

(Business manager working at a factory supplying M\&S) Moralities around health have direct commercial consequences. Health marketing messages have been a central platform around which retailers have demonstrated their commitment to voluntary regulatory targets and these measures legitimize their authority to act free from more punitive regulatory constraints and confer their status as 'custodian[s] of quality' within the neoliberal marketplace (Dixon, 2003, p. 34). Manufacturers maintained such a position contrasts to the ways ready-made foods used to be viewed as unhealthy and processed 'slop' and is a result of their concerted efforts to 'moralize' this market, as well as mobilize the consumer to utilize these resources to construct herself as a good mother and cook.

\section{Gender, guilt and ready-to-cook markets}

That the consumer of ready-made foods is female is an enduring feature of the way markets for ready-made foods developed. Women are the primary providers of foodwork within the home and although the feminist movement and economic changes in the 1970s began to challenge this expectation, women continue to define their identities and symbolically constitute their families through the foodwork they perform (Charles and Kerr, 1988; DeVault, 1991; Moisio, Arnould and Price, 2004; Short, 2006; Cairns and Johnston, 2015). Yet tensions remain as women try to perform this caring role at the same time as working and bringing up a family. These tensions were often reflected upon in the situation of the focus group: 
Lorna: I think there's definitely a bell of a lot more ready-made stuff, 'cos we always have less time than say in the old days, you used to get mums sort of stay at home and make the food, whereas these days most women work and so we haven't got the time to do everything from scratch. So there's a big market for the ready-made stuff.

Carly: Everyone's exhausted all the time, whereas the women in the 1950s had much more time for sex and cooking (laughter), we're just always knackered. So aren't we clever?

(Lorna, aged 30, solicitor and Carly, aged 45, social worker with children at home) These professional women both justify and denigrate the use of ready-made foods in relation to changing feminine identities. On the one hand, ready-made foods allow these women to provide for their husbands and children at the same time as working outside of the home, yet on the other, these transformations are a source of regret and invoke a call to revalue the domestic sphere as a site of female empowerment.

Like Cairns and Johnston's (2015: p160) study (and DeVault's before this), the women we interviewed got emotional satisfaction from cooking 'properly' and 'performing hegemonic femininity through food'. It was this valuing of feminine foodwork that seemed to generate feelings of guilt when our respondents sought to justify why they needed to use ready-made foods in the context of their busy everyday lives. For Amanda, a stay-at-home mother in her thirties with two small boys, 'it's a source of pride to cook nice food for them' but there are times when everyday life gets intervenes. On the day of the interview Amanda had gotten up early to make pizza dough ready for the boys to add toppings in the evening, but they had gone to the park and come home later than expected. Amanda needed 'a quick tea' so she boiled up some gnocchi with a jar of pesto; she said 'they like the jar stuff, honestly I've made pesto twice in the last few months and Jack wouldn't eat it'. A similar story is told by Jacqui, a full-time lawyer and mother of two who invests a lot of time cooking 'decent meals' and describes how she's always buying cookbooks in the hope she'll find a recipe for a quick meal she can make from raw ingredients. Yet she admits that in the middle of a trial, 'I have been known to buy a 
pre-prepared fish pie'. These women drew on material and cultural resources to position themselves as mothers in control of their children's diets through their exercise of healthy food choices. It is important to highlight that women from different socio-economic backgrounds are not equally enabled to occupy this position. Take Ivy, mother of three, unemployed and claiming benefits, who really wants to feed her children 'decent food'. She receives Healthy Start vouchers (state-aided purchase of fresh vegetables and fruits) but finds it difficult to get her children to eat fresh foods. She watches cookery programs for ideas of what to make, and buys jars of sauces for the recipes on the back but admits it's a struggle to always cook fresh food because 'I'd like to have more choice in my cupboards than what I actually need'.

As we have seen, food manufacturers are quite aware women feel guilty about using ready-made foods, but it was interesting how they described a shift in the underlying context behind this guilt. Whilst 50 years ago, the housewife felt guilty because she was 'spending her housekeeping on stuff that she could have made herself, now she feels guilty because readymade foods are considered to be unhealthy in a society that places blame upon those who do not take individual responsibility for their health. Of course, manufacturers were keen to dispel the assumption that ready-made food was unhealthy claiming (in response to government guidance) the only ingredients you'll find in ready-made foods are those found 'in the housewife's storecupboard'. Yet at the same time, their understanding of the consumer and the market was framed through the lens of individual choice, in keeping with models of neo-liberal selfgovernance.

people want to be able to be involved in what they're eating, and be in control of what they're eating [...]I think what we have probably done, in the food industry today is we have taken away personal responsibility for everything, and this traffic lighting, all this nutritional information, hopefully will put some personal responsibility in there

(Assistant Director at a factory supplying M\&S). 
That people should know where their food has come from and had a role in the cooking process reflects broader moralizing discourses circulated through media channels in the form of lifestyle professionals and celebrity chefs, as well as through government and NGO- supported cooking classes(Johnston and Goodman, 2015). Being in control of your own and your family's health is an individual feminine responsibility, yet at the same time, we find a persistent societal concern that women no longer know how to cook or take control of their diet because of the growth of ready-made food market (Lang and Caraher, 2001; Short, 2006). As manufacturers are being blamed for eroding people's cooking skills, there is a need to respond to this moral critique and demonstrate their responsibility by providing the resources that will mobilize the 'uneducated housewife' to learn to cook using their foods. These cook your own meal solutions, alongside recipe suggestions using prepared ingredients, are often endorsed by those celebrity chefs who play a role in perpetuating the discourse (or moral panic) of a decline in cooking skills. This is another example of how moral narratives are used to create new moral economies, shaped by idealized images of what it means to be a good mother and cook and in response to societal moralizing around declining cooking skills at the level of collective customs. Possibilities are opened through these innovations for new meanings and moralities of ready-made and fresh food to circulate and be performed.

Turning our focus back to the moral economy framework to understand these innovations, evolving meanings and conventions around cooking and femininity, the discussions above have shown all three layers of the framework need to be explored as a relational complex if we are to understand the moral economy of ready-made foods. Starting from the level of state regulation, we have seen how ideas about individual responsibility and retailer self-governance have started to transform the market towards fresher, healthier ready-made/ready-to-cook food options. These have been developed in part because consumers - particularly women - feel guilty about serving ready-made foods to their family for whom they should act as guardian of health and tastes (Cairns and Johnston, 2015). They feel guilty because a range of institutions 
(such as celebrity chefs, government, and alternative consumption movements) are constructing processed and convenience foods as unhealthy and unsustainable at the layer of collective customs, and are representing the 'solution' as one that is in the hands of individuals who can enact their individual responsibility through cooking from fresh ingredients (Johnston and Goodman, 2015). They also feel guilty because performing this 'hegemonic femininity' of the mother/wife who is in control must be negotiated in the context of daily contingencies and material and cultural constraints. These three layers (or circles) are floating around the funnel of the instituted system of ready-made food provision which is characterised by supermarket dominance (see figure 1), and they are colliding with each other, shaping one another and transforming meanings and moralities of ready-made foods. Opportunities and constraints are realized in the dynamic interactions between these layers and possibilities are opened for new moralities and identities to be performed, as well as new systems of provision to be created as a result.

\section{Conclusion}

This paper has made a case for using a multi-layered framework to understand how morals and markets are co-constituted. Forging a bridge between economic sociology and the sociology of consumption, I have argued that morals and markets are best explored as continually negotiated social and political projects, shaped by various forces - including societal critiques of consumption and consumers, institutional frameworks, cultural conventions and the everyday reflections of consumers. I have used the example of ready-made foods to show why such a framework is needed. Food is often explored through the lens of individual choice and 'bad' food choices are considered the fault of those who make them. Yet how certain foods come to be seen as 'bad' at the individual and societal level and how the market responds to such claims needs to be analysed as a result of a complex series of interactions between actors operating at different scales and 
locations with differing levels of material and cultural power. By adopting such a multi-layered perspective, the focus is shifted away from those individual food choices to the policies, the discourses and the everyday contingencies through which food consumption is framed and experienced.

The framework developed in this paper is designed to be attentive to the ways moralities of consumption develop through a process of continuous negotiation at the macro, meso and micro levels. The moral economy is revealed as a relational concept that comes into being through the interactions and interdependencies between individuals, communities and political-economic structures. All three layers must be analysed if we are to understand how moralities and markets are co-constituted. In the case of ready-made foods, if we were to only pay attention to state regulation and discuss the effect of neo-liberal policies on the ways foods are made healthier for individuals, we miss how ideas of health and responsibility come to shape the discussion of food cultures at a collective level, and how individuals make these values matter through their everyday enactment of care and foodwork in the context of material and cultural constraints. If we only focus on the ways lifestyle practitioners, media and NGOs mobilize within the foodscape, we miss how ideas about what it means to be a good cook/mother might be transformed through market innovations that respond to state regulations around healthfulness, and how meanings around ready-made may shift when consumers start using ready-made foods in creative ways. If we were to only concentrate on exploring the feelings of guilt and pleasure women experience when trying to provide good food for their family and live up to idealized scripts of femininity, we ignore how opportunities might be created (and stalled) to enact alternative moralities through market devices that aim to transform what it means to cook/eat well and be a good mother. In short, it is in these relations between everyday evaluations of what matters in the context of daily contingencies and material constraints that we see how normative visions of appropriate consumer behaviour are negotiated, defended and challenged using existing cultural and moral repertoires to create new markets. 
This paper has focused on the UK market which is shaped by several distinctive features. But the moral economy framework is a powerful tool for exploring the distinctive configuration of morals and markets in comparative contexts. Forms of consumer mobilization and state regulation vary within socio-cultural and national contexts, with British consumers organized within a neo-liberal economy embracing the ideology of the active citizen-consumer much more than those in German, Nordic, and Latin American contexts (Wheeler, 2012, 2014; Ariztía et al., 2014; Jackson, 2015). For example, in Taiwan ready-made foods are popular and have been largely provisioned through convenience stores and informal street vendors operating within a context of limited state regulation and limited discussions of consumer morality (Glucksmann, 2014). When researching moral economies in comparative contexts, the framework captures this varying relationship between the state, commercial domain, civil society and individual consumers to consider how these interactions together create norms around consumption.

In sum, this paper argues any attempt to understand the moral economy must pay attention to all three layers of this analytical framework (state regulation of the market, collective customs and lay normativities) and how they are instituted within a distinct instituted system of provision. By exploring the interactions between and within these levels - the interplay, the challenges and the acceptance - we gain greater understanding of the place of morality within the economy.

\section{Notes}

1. The author would like to thank Professor Miriam Glucksmann for both providing me with access to her previous project data and encouraging me to use this in tandem with our later project to develop my ideas on moral economy further. I also owe Miriam much thanks for her continued support, as well as for her comments on earlier drafts of this paper. I have used research data from the ESRC project 'Transformations of Work: New Frontiers, Shifting 
Boundaries, Changing Temporalities' research programme. (RES-051-27-0015) led by Professor Miriam Glucksmann. The remainder of the data was gathered during the project funded by an ERC Advanced Investigator Grant, led by Professor Miriam Glucksmann: 'Consumption Work and Societal Divisions of Labour' (DivLab 249430).

2. Data from household food diaries identified purchases of meat, fish and vegetable readymeals and this was mapped onto household level socio-demographic data over 10 years of the survey between $2001 / 2$ to 2011 .

\section{References}

Abbots, E. J. (2015) 'The intimacies of industry: Consumer interactions with the "stuff" of celebrity chefs', Food, Culture and Society, 18(2), pp. 223-243. doi: 10.2752/175174415X14180391604323.

Adams, M. and Raisborough, J. (2010) 'Making a difference: Ethical consumption and the everyday', British Journal of Sociology, 61(2), pp. 256-274. doi: 10.1111/j.14684446.2010.01312.x.

Ariztía, T. et al. (2014) 'Ethical consumption in Brazil and Chile: Institutional contexts and development trajectories', Journal of Cleaner Production, 63, pp. 84-92. doi: 10.1016/j.jclepro.2013.04.040.

Bandelj, N. (2012) 'Relational Work and Economic Sociology', Politics \& Society, 40(2), pp. 175201. doi: $10.1177 / 0032329212441597$.

Barnes, C. (2014) 'Mediating good food and moments of possibility with Jamie Oliver: Problematising celebrity chefs as talking labels', Geoforum. Elsevier Ltd. doi: 10.1016/j.geoforum.2014.09.004.

Block, F. and Polanyi, K. (2003) 'Karl Polanyi and the Writing of "The Great Transformation"”, 
Theory and Society, 32(3), pp. 275-306.

Bolton, S. C. and Laaser, K. (2013) 'Work, employment and society through the lens of moral economy', Work, Employment \& Society, 27(3), pp. 508-525. doi: $10.1177 / 0950017013479828$.

Braun, V. and Clarke, V. (2006) 'Using thematic analysis in psychology Using thematic analysis in psychology', 3(2), pp. 77-101. doi: 10.1191/1478088706qp063oa.

Bugge, A. B. and Almås, R. (2006) 'Domestic dinner: Representations and practices of a proper meal among young suburban mothers', Journal of Consumer Culture, 6(2), pp. 203-228. doi: $10.1177 / 1469540506064744$.

Burch, D. and Lawrence, G. (2005) 'Supermarket own Brands, Supply Chains and the Transformation of the Agri-Food System', International Journal of Sociology of Agriculture and Food, 13(1), pp. 1-18.

Cairns, K. and Johnston, J. (2015) Food and Femininity. London: Bloomsbury.

Callon, M. (1998) 'The laws of the markets. Introduction: The embeddednes of economic markets in economics', The Sociological Review, 46(S1), pp. 1-58. doi: 10.1111/j.1467954X.1998.tb03468.x.

Callon, M., Millo, Y. and Muniesa, F. (eds) (2007) Market Devices. Oxford: Blackwell Publishing. Carrigan, M., Szmigin, I. and Leek, S. (2006) 'Managing routine food choices in UK families: The role of convenience consumption', Appetite, 47(3), pp. 372-383. doi: 10.1016/j.appet.2006.05.018.

Charles, N. and Kerr, M. (1988) Women, food and families. Manchester: Manchester University Press.

Cook, I. (2004) 'Follow the Thing: Papaya', Antipode, 36(4), pp. 642-664. doi: 10.1111/j.14678330.2004.00441.x.

Corti, L. et al. (2014) Managing and Sharing Research Data. London: Sage.

Defra (2010) Food 2030. London. Available at: 
http://www.defra.gov.uk/foodfarm/food/strategy/.

DeVault, M. (1991) Feeding the family: the social organisation of caring as gendered work. Illinois:

University of Chicago Press.

Dixon, J. (2003) 'Authority, power and value in contemporary industrial food systems', International Journal of Sociology of Agriculture \& Food, 11(1), pp. 31-39.

Evans, D. (2014) Food waste. London: Bloomsbury. doi: SNSC 07045.

Fine, B. and Leopold, E. (1993) The World of Consumption. London: Routledge.

Fourcade, M. and Healy, K. (2007) 'Moral Views of Market Society', Annual Review of Sociology, 33(1), pp. 285-311. doi: 10.1146/annurev.soc.33.040406.131642.

Gatley, A., Caraher, M. and Lang, T. (2014) 'A qualitative, cross cultural examination of attitudes and behaviour in relation to cooking habits in France and Britain', Appetite. Elsevier Ltd, 75, pp. 71-81. doi: 10.1016/j.appet.2013.12.014.

Gereffi, G. and Lee, J. (2009) A Global Value Chain Approach To Food Safety And Quality Standards. Available at: https://pdfs.semanticscholar.org/308f/7ea15215c95c104d24f865db1329f0b9c148.pdf.

Glucksmann, M. (2014) 'Bake or buy? Comparative and theoretical perspectives on divisions of labour in food preparation work', Anthropology of food, p. Online. doi: $10.1177 / 053901847901800604$.

Goodman, M. K. (2004) 'Reading fair trade: Political ecological imaginary and the moral economy of fair trade foods', Political Geography, 23(7), pp. 891-915. doi: 10.1016/j.polgeo.2004.05.013.

Goodman, M. K., Maye, D. and Holloway, L. (2010) 'Ethical Foodscapes?: Premises, Promises and Possibilities', Environment and Planning A, 42, pp. 1782-1796.

Granovetter, M. (1985) 'Economic action and social structure: the problem of embeddedness', American journal of sociology, 91(3), pp. 481-510.

Halkier, B. (2016) 'Normalising convenience food? The expectable and acceptable places of 
convenient food in everyday life among young Danes', Food, Culture \& Society. Routledge, Online Fir(November), pp. 1-19. doi: 10.1080/15528014.2016.1243768.

Harvey, M. (2007) 'Instituting economic processes in society', in Harvey, M., Ramlogan, R., and Randles, S. (eds) Karl Polanyi: New perspectives on the place of economy in society. Manchester: Manchester University Press, pp. 163-184.

Harvey, M., Quilley, S. and Beynon, H. (2002) Exploring the Tomato. Cheltenham: Edward Elgar. Hollows, J. and Jones, S. (2010) ““At least he”s doing something': Moral entrepreneurship and individual responsibility in Jamie's Ministry of Food', European Journal of Cultural Studies, 13(3), pp. 307-322. doi: 10.1177/1367549410363197.

Holm, L. et al. (2015) 'Who is Cooking Dinner?', Food, Culture \& Society. Routledge, 18(4), pp. 589-610. doi: 10.1080/15528014.2015.1088191.

Jackson, P. (2015) Anxious Appetites: Food and Consumer Culture. London: Bloomsbury.

Jackson, P., Ward, N. and Russell, P. (2009) 'Moral economies of food and geographies of responsibility', Transactions of the Institute of British Geographers, 34(1), pp. 12-24. doi: 10.1111/j.1475-5661.2008.00330.x.

Johnston, J. and Goodman, M. K. (2015) 'Spectacular foodscapes: food celebrities and the politics of lifestyle mediation in an age of inequality', Food, Culture and Society, 18(2), pp. 205-222. doi: 10.2752/175174415X14180391604369.

Key Note (2013) Ready meals market report plus 2013. Richmond Upon Thames.

Lang, T., Barling, D. and Caraher, M. (2009) Food Policy: Integrating health, environment and society. Oxford: Oxford University Press.

Lang, T. and Caraher, M. (2001) 'Is there a culinary skills transition? Data and debate from the UK about changes in cooking culture', Journal of Home Economics Institute of Australia, 8(2), pp. 2-14.

Lavis, A., Abbots, E. J. and Attala, L. (2015) 'Reflecting on the Embodied Intersections of Eating and Caring', in Abbots, E., Lavis, A., and Attala, L. (eds) Careful Eating: Bodies, Food 
and Care. London: Routledge, pp. 1-21.

Marsden, T. et al. (2010) The New Regulation and Governance of Food: Beyond the food crisis? London: Routledge. doi: 10.1017/CBO9781107415324.004.

Miller, D. (1998) A Theory of Shopping. Cambridge: Polity Press.

Moisio, R., Arnould, E. J. and Price, L. (2004) 'Between Mothers and Markets: Constructing family identity through homemade food', Journal of Consumer Culture, 4(3), pp. 361-384. doi: $10.1177 / 1469540504046523$.

Morgan, K. (2015) 'The moral economy of food', Geoforum. Elsevier Ltd, 65, pp. 294-296. doi: 10.1016/j.geoforum.2015.07.029.

North, A. (2015) 'Ready Meals Category Report 2015’, The Grocer, 21 February, p. 49.

Polanyi, K. (1944) The Great Transformation. Massachusetts: Beacon Press.

Polanyi, K. (1957) 'The Economy as Instituted Process', in Polanyi, K., Arensberg, C., and Pearson, H. (eds) Trade and Market in the Early Empires. Illinois: The Free Press, pp. 243269.

Prior, G., Phillips, R. and O’Driscoll, C. (2014) The 2014 Food and You Survey. Available at: http://www.food.gov.uk/sites/default/files/food-and-you-2014-uk-bulletin-1.pdf.

Rousseau, S. (2012) Food Media: Celebrity Chefs and the politics of everyday interference. London: Bloomsbury.

Sayer, A. (2000) 'Moral Economy and Political Economy', Studies in Political Economy, 61, pp. 79_ 103.

Sayer, A. (2005) The Moral Significance of Class. Cambridge: Cambridge University Press.

Sayer, A. (2011) Why things matter to people: Social science, Values and Ethical Life. Cambridge: Cambridge University Press.

Short, F. (2006) Kitchen Secrets: The meaning of cooking in everyday life. Oxford: Berg.

Szabo, M. K. (2013) ‘Foodwork or Foodplay? Men’s Domestic Cooking, Privilege and Leisure’, Sociology, 47(4), pp. 623-638. doi: 10.1177/0038038512448562. 
Thompson, E. P. (1971) 'The Moral Economy of the English Crowd in the Eighteenth Century', Past and Present, 50, pp. 76-136.

Trentmann, F. (2007) 'Before "fair trade": Empire, free trade, and the moral economies of food in the modern world', Environment and Planning D: Society and Space, 25(6), pp. 1079-1102. doi: $10.1068 / \mathrm{d} 448 \mathrm{t}$.

Warde, A. (1997) Consumption, food and taste. London: Sage.

Warde, A. (1999) 'Convenience food: space and timing', British Food Journal, 101, pp. 518-527. doi: 10.1108/00070709910279018.

Wheeler, K. (2012) Fair Trade and the Citizen-Consumer: Shopping for Justice. Hampshire: Palgrave Macmillan. doi: 10.1057/9781137283672.

Wheeler, K. (2014) 'Nice save: The moral economies of recycling in England and Sweden', Environment and Planning D: Society and Space, 32(4), pp. 704-720. doi: 10.1068/d18912.

Wheeler, K. (2017) 'Moral economies of consumption', Journal of Consumer Culture, 0(0), pp. 1-18. doi: $10.1177 / 1469540517729007$.

Wilson, M. and Jackson, P. (2016) 'Fairtrade bananas in the Caribbean: Towards a moral economy of recognition', Geoforum. Elsevier Ltd, 70, pp. 11-21. doi: 10.1016/j.geoforum.2016.01.003.

Zelizer, V. A. (2011) Economic Lives: How culture shapes the economy. Princeton: Princeton University Press. 